\title{
Liquefaction hazard zonation mapping of the Saitama City, Japan
}

\author{
*Rama Mohan Pokhrel, Jiro Kuwano, and Shinya Tachibana \\ Geosphere Research Institute, Department of Civil and Environmental Engineering \\ Saitama University, Japan \\ (*Email:pokhrel_rmohan@yahoo.com)
}

\begin{abstract}
Liquefaction hazard zonation mapping of the Saitama City targeted on the Kanto Plain NW Edge Fault is described in this paper. The study involves the geotechnical properties of the alluvial soil of the city including Standard Penetration Test (SPT), shear wave velocity and other geological data analysis. The city being highly urbanized is situated on the soft soil (alluvial deposits) at the proximity of an active seismic fault that has increased the possibility of liquefaction hazard in the area. Kanto Plain NW Edge Fault is an active fault that lies very near to the Saitama City having the estimated possible earthquake magnitude of 7.4. The possible peak horizontal ground acceleration $\left(a_{m a x}\right)$ from this earthquake is calculated as from $0.15 \mathrm{~g}$ to $0.30 \mathrm{~g}$. By considering all possible acceleration values the liquefaction potential maps were prepared and presented in this paper. Additionally, the shear wave velocity is very low and amplification ratio is very high at the marshy deposit but it has comparatively high velocity and low amplification ratio at the marine loam deposit area of the Omiya Plateau. In this paper the liquefaction potential of the area is expressed in terms of liquefaction potential index $\left(P_{L}\right)$. The $P_{L}$ value for the clayey silt deposit in the marshy area with shallow water table is very high. In addition, the $\mathrm{P}_{\mathrm{L}}$ value in the marine loam deposit of the Omiya Plateau is less which indicates that loam deposit has less liquefaction potential than marshy deposit. The map obtained from this study was validated with the field condition of the study area. Hence, it is expected that this study will assist in characterizing the seismic hazards and its mitigation and will provide valuable information for urban planning in the study area in future.
\end{abstract}

Keywords: Standard Penetration Tests (SPT), liquefaction potential, Peak Horizontal Ground Acceleration (PHGA), shear wave velocity, Saitama City, Japan

Recieved: December 18, 2009

Revision accepted: April 27, 2010

\section{INTRODUCTION}

Soil liquefaction is one of the most devastating types of geotechnical effects induced by the earthquake. It causes failure of foundations, embankments and dams, these failures ultimately affect the social and financial status of the region. The Niigata earthquake of 1964 and Kobe earthquake of 1985 were the recent most devastating events that induced liquefaction effect in Japan. These cases have stressed the need for assessment of liquefaction potential of seismically active sites in the world. The effects of soil liquefaction due to earthquake have been highlighted since 1964 after Niigata earthquake in Japan and have been made to understand soil liquefaction behaviors since then.

Liquefaction hazard zonation mapping is the process of identification of the area with different liquefaction hazard potentials. It is the process for estimating the response of soil layers under earthquake excitations and the variation of earthquake acceleration characteristics on the ground surface. The main purpose of this study is to prepare a liquefaction hazard zonation map which may help to identify significantly the possible zone of severe disaster and ground disturbances during seismic events and thus helping to provide basic information of ground properties for seismic design of structures. Information about areas with highly likelihood of ground deformation can be used for effective regional earthquake hazard mitigation planning. Liquefaction hazard zonation is the most important step towards a seismic risk analysis and mitigation strategy in the densely populated urban areas. Liquefaction hazard maps are also useful for identifying areas, where specific investigations for liquefaction hazard are needed prior to project development but in general these maps should not be used for site-specific purpose of engineering designs.

Japan is situated in the seismically very active zone. This country is located in marginal areas of the Pacific Ocean and Philippine Sea, which lies in North American and Eurasian Plates. Because of seismic activity the country is frequently struck by the major earthquakes. The Saitama City is situated in the middle part of the great Kanto Plain of Japan. It is a sedimentary basin filled with the Neogene and Quaternary sediments and surrounded by Kanto Mountains of preNeogene and early Miocene rocks. The Quaternary units at the Saitama City mostly consist of silt and sand. Due to presence of soft soil layers, the ground surface can be significantly amplified by the cause of seismic activities. However, such ground responses are closely related with the local soil profile and geotechnical properties of the soil. 


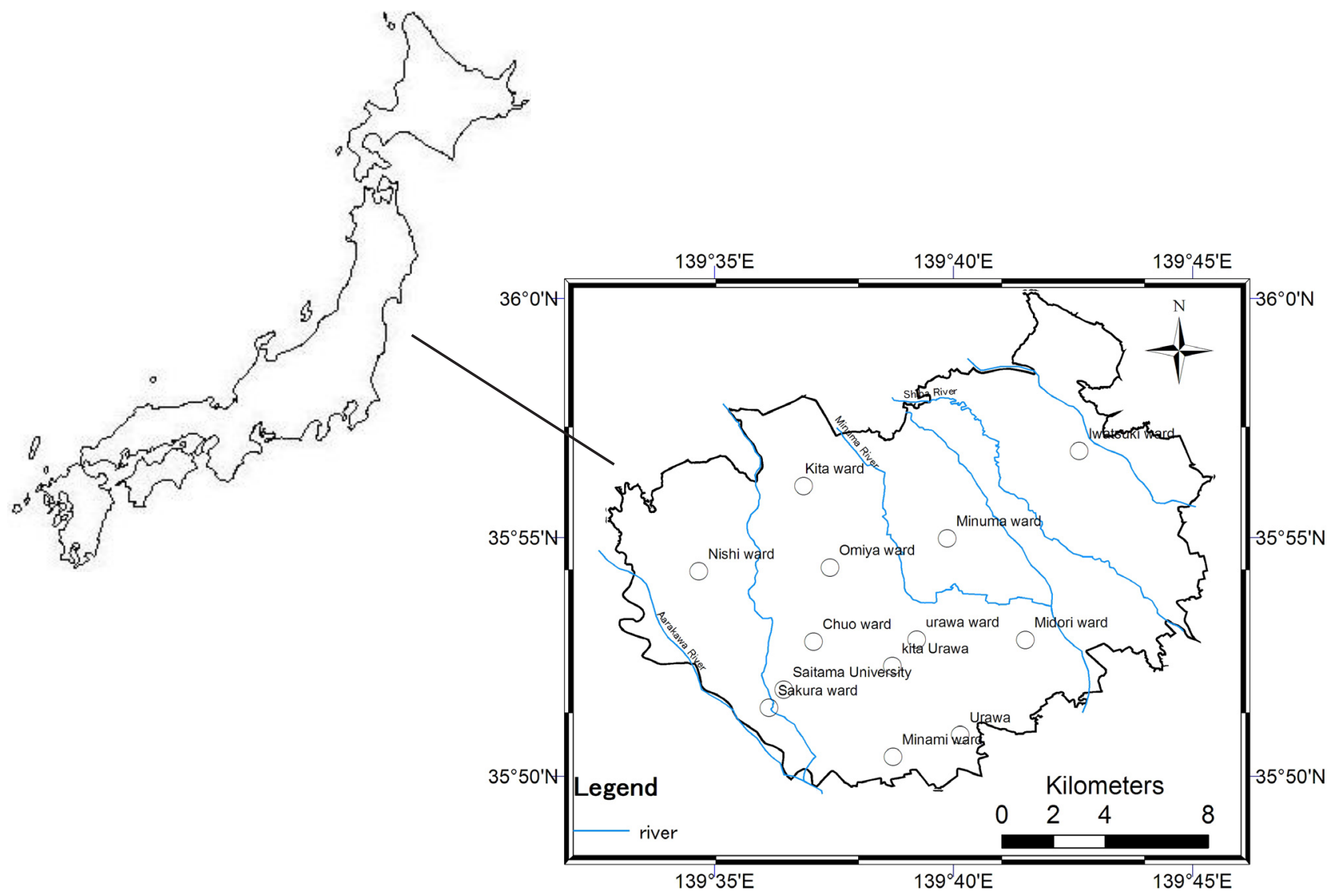

Fig . 1: Location map of the Saitama City (study area)

The loose sediments (silt and fine sand) are favorable to liquefaction at the time of the earthquake. Large amplification of the seismic signals generally occurs in areas where layers of low seismic velocity overlie materials with high seismic velocity, i.e. where soft sediments cover the bedrock or more stiff soils.

The regional geology plays an important role for type of effects and characteristic ground motion during earthquake. The source, travel path and local site effects mainly influence earthquake-related ground motions at a particular site (Kienzle et al. 2006). In the case of Saitama City the source effects (focal mechanism, size, and directivity) and travel path effects can be considered constant for the entire city area. Therefore, site effects must be assumed to cause the variation of ground motion within the city area. The site responses of the ground motion may vary in different locations of the area according to the local geology. The distribution of various soil properties, such as the thickness of weak sand layer and SPT N values have strong influence on liquefaction potential.

The Saitama City has been affected by several destructive earthquakes of about $M>8$ in the past. The latest great earthquake that hit the area was great Kanto earthquake of magnitude of 8.3 in 1923 A.D. This earthquake had devastated Tokyo City, the port city of Yokohama, surrounding prefectures of Chiba, Kanagawa, and Shizuoka, and caused widespread damage throughout the Kanto region (Hammer 2006). The Saitama City being highly urbanized is situated on the alluvial deposits. Presence of active fault to its proximity has demanded the necessity of study for liquefaction potential assessment in the area.

Liquefaction hazard maps can be grouped into four general categories: historic maps, susceptibility maps, potential maps, and ground failure maps (Power and Holzer 1996). Historic maps identify areas where liquefaction has occurred in the historic past and will likely to occur again. Susceptibility map identifies areas with materials that can liquefy based on historic information, geology (e.g., environment of deposition, age of deposit, and depth to groundwater table), composition, and initial density (Youd and Hoose 1977; Youd and Perkins 1978). Potential map considers both the susceptibility of the deposit and the earthquake ground shaking either for a certain exposure time period or a scenario earthquake. Ground failure map attempts to predict the amounts of liquefaction-induced permanent ground displacements associated with an exposure time period or a scenario earthquake in the area. 


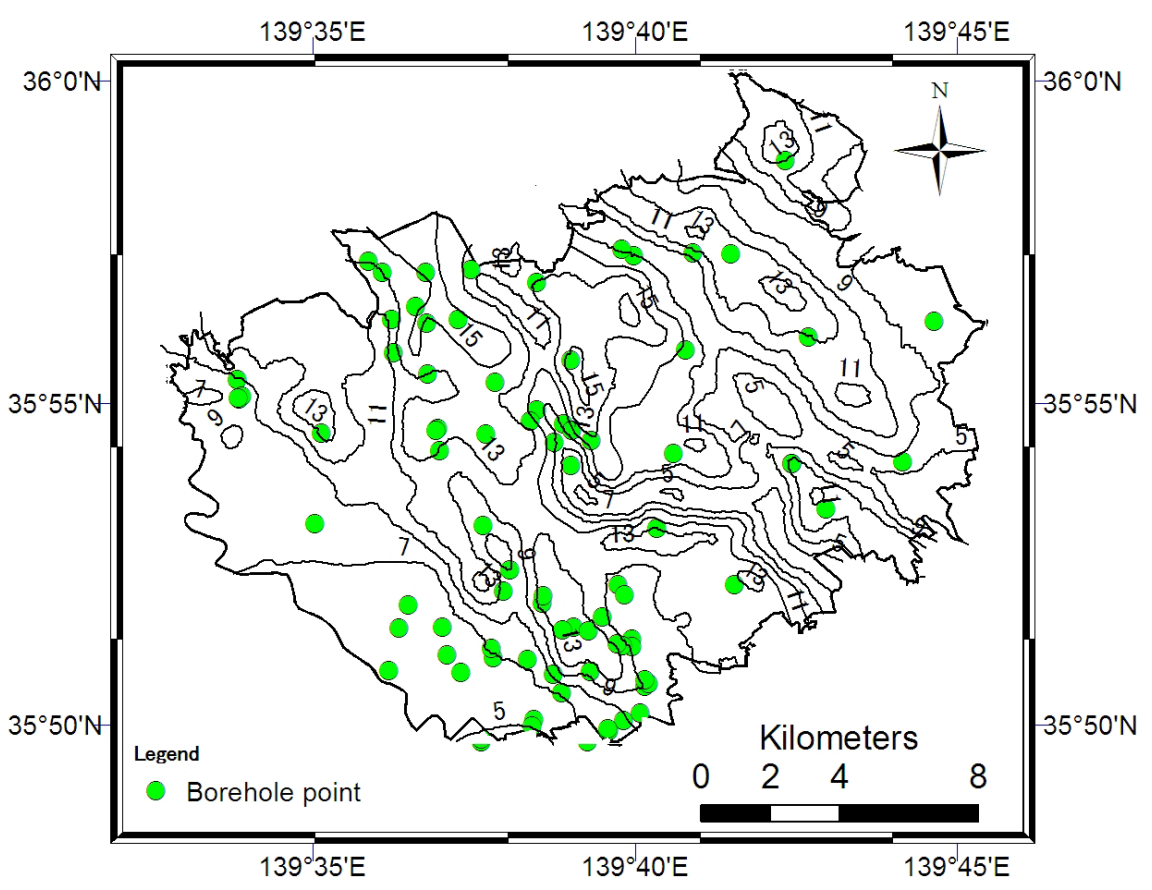

Fig. 2: Contour map of the study area with location of boreholes

This study concentrates on the assessment of the liquefaction potential of soil deposits at Saitama City by using analyses of more than 200 borehole data. Geographical Information System (GIS) was used for the preparation of geotechnical database and preparation of the maps. The simple spread sheet has been generated for SPT N-value corrections, calculation of factor of safety and liquefaction potential index. Based on the factor of safety, the liquefaction potential index has been calculated by assuming Kanto Plain NW Edge fault earthquake with magnitude of 7.4 and epicenter distance of $50 \mathrm{~km}$. The hazard maps were generated for the possibility of maximum ground acceleration of $0.15 \mathrm{~g}$, $0.2 \mathrm{~g}, 0.25 \mathrm{~g}$ and $0.3 \mathrm{~g}$. An ordinary Kriging method in GIS was used for the prediction of the liquefaction potential map. The category associated with the liquefaction potential index $\left(\mathrm{P}_{\mathrm{L}}\right)$ value at each boring location was used in the analysis.

\section{STUDY AREA}

The present study area is located in the Saitama City, the capital and most populated city of Saitama prefecture in Japan (Fig. 1). The geographic position of the study area extends from $35^{\circ} 49^{\prime} 43.72^{\prime \prime}$ to $36^{\circ} 00^{\prime} 9.23^{\prime \prime} \mathrm{N}$ and $139^{\circ} 32^{\prime} 13.28^{\prime \prime}$ to $139^{\circ} 45^{\prime} 23.99^{\prime \prime} \mathrm{E}$ with total area of $217.49 \mathrm{sq} . \mathrm{km}$. The city is topographically comprised of lowlands and plateaus, mostly falling below $20 \mathrm{~m}$ above sea level in the middle part of the great Kanto Plain of Japan (Fig. 2). The western portion of the city lies on the lowland created by the Arakawa River. The middle portion mostly lies on Omiya Plateau. The sediments of the Omiya Plateau are marine loam deposits (Machida 1999). The depth of the bed rock in the study area is below $3500 \mathrm{~m}$ from the ground surface (J-SHIS 2009).

\section{METHODOLOGY}

\section{Geotechnical Data}

The basic data for evaluating the liquefaction potential such as type of soil, SPT N-values, the depth of water table, mean grain size and unit weight of soil were collected from subsoil investigation reports that were compiled by various government agencies, local public body and private consultants, and some of the data were collected from the internet access. The locations of the borehole and geotechnical data with ground level are shown in the Fig. 2. The borehole data in the study area were collected from different depths ranging $15 \mathrm{~m}$ to $100 \mathrm{~m}$ below ground surface. For the purpose of the study, geotechnical database upto $20 \mathrm{~m}$ depth below gound surface is used. The liquefaction properties of layer below $20 \mathrm{~m}$ delpth do not affect the surface, so it is not considered. The borehole data includes various types of unconsolidated materials such as clay, silt, sand, gravel, volcanic ash, organic material, loam and their mixtures. The subsoil of the Saitama City area is divided into five different layers on the basis of dominant soil type, SPT Nvalue and geotechnical properties of the soil. The different layers and their liquefaction potential are given in Table 1.

Typical litholog of the study area is shown in Fig. 3. It is interpreted that the upper layer of the ground is very loose and consists of mostly silt and sand which is highly susceptible to liquefaction at the time of an earthquake (Fig. 3). The figure shows that $\mathrm{N}$ value is greater than 50 at the depth below $25 \mathrm{~m}$ which indicates that the soil at that depth is compacted and is non liquefiable compared to the upper layer. 
Table 1: Types of soil and level of liquefaction potential in the Saitama City area

\begin{tabular}{|c|c|c|c|}
\hline $\begin{array}{l}\text { Type of soil } \\
\text { layer }\end{array}$ & Type of soil & $\mathbf{N}_{\mathrm{m}} *$ Value & $\begin{array}{c}\text { Liquefaction } \\
\text { potential }\end{array}$ \\
\hline Soft Layer A & $\begin{array}{l}\text { Silt dominated soil, } \\
\text { like clayey silt, pure } \\
\text { silt, sandy silt }\end{array}$ & $\leq 10$ & High \\
\hline Soft layer B & $\begin{array}{l}\text { Clay dominated soil, } \\
\text { like clay, silty clay, } \\
\text { sandy clay }\end{array}$ & $\leq 10$ & Medium \\
\hline Soft layer C & $\begin{array}{l}\text { Sand dominated soil, } \\
\text { like fine, medium } \\
\text { and coarse sand, } \\
\text { silty sand, clayey } \\
\text { sand, }\end{array}$ & $\leq 10$ & High \\
\hline Hard layer A & $\begin{array}{l}\text { Sand dominated soil, } \\
\text { like fine, medium } \\
\text { and coarse sand, }\end{array}$ & $\geq 10$ & Low \\
\hline Hard layer B & $\begin{array}{l}\text { Gravel dominated } \\
\text { layer, like sandy } \\
\text { gravel, pure gravel }\end{array}$ & $\geq 50$ & No Liquefaction \\
\hline
\end{tabular}

$N_{m}^{*}$ is measured SPT value in the field

\section{Corrections of $\mathrm{N}$-values and factor of safety}

The factor of safety against liquefaction of the soil layer has been evaluated based on the simplified procedure proposed by Seed and Idriss (1971) and summarized by Youd et al. (2001) based on SPT-N values and Cyclic Stress Ratio (CSR) calculated using stress reduction factor. In this method, the earthquake induced loading is expressed in terms of the (CSR) and is compared with the liquefaction resistance of the soil.

CSR was calculated based on most widely used simplified approach recommended by Seed and Idriss (1971) and summarized by Youd et al. (2001).

Cyclic Stress Ratio (CSR)

$\frac{\tau_{a v}}{\sigma_{0}^{\prime}}=0.65 \frac{\sigma_{0}}{\sigma_{0}^{\prime}} \frac{a_{\max }}{g} \gamma_{d}$

The parameter $o$ and $o^{\prime}$ are the total and effective overburden stresses, respectively; $\mathrm{g}$ is the acceleration due to gravity; $a_{\max }$ is the Peak Horizontal Ground Acceleration generated by an earthquake; the $a_{\max }$ value for an earthquake were estimated by using the relation purposed by Boore et al. (1993) and is the stress reduction factor (Youd et al. 2001).

$\gamma_{d}=\frac{\left(1.0-0.4113 z^{0.5}+0.04052 z+0.001753 z^{1.5}\right)}{\left(1-0.4177 z^{0.5}+0.05729 z-0.006205 z^{1.5}+0.001210 z^{2}\right)}$.

Where, $\mathrm{z}$ is depth from the ground surface.

For liquefaction analysis $\left(\mathrm{N}_{1}\right)_{60}$ values are used as standard $\mathrm{N}$-values (Seed et al. 1985), $\left(\mathrm{N}_{1}\right)_{60}$ values are the corrected $\mathrm{N}$-values. The $\left(\mathrm{N}_{1}\right)_{60}$ values are calculated by the formula:

$\left(N_{1}\right)_{60}=C_{n} \frac{E R_{m}}{60} N_{m}$
Table 2: $\mathrm{C}_{\mathrm{n}}$ correction coefficient for overburden pressure at $40-60 \%$ and $60-80 \% D_{r}$ Values (after Seed et al. 1984)

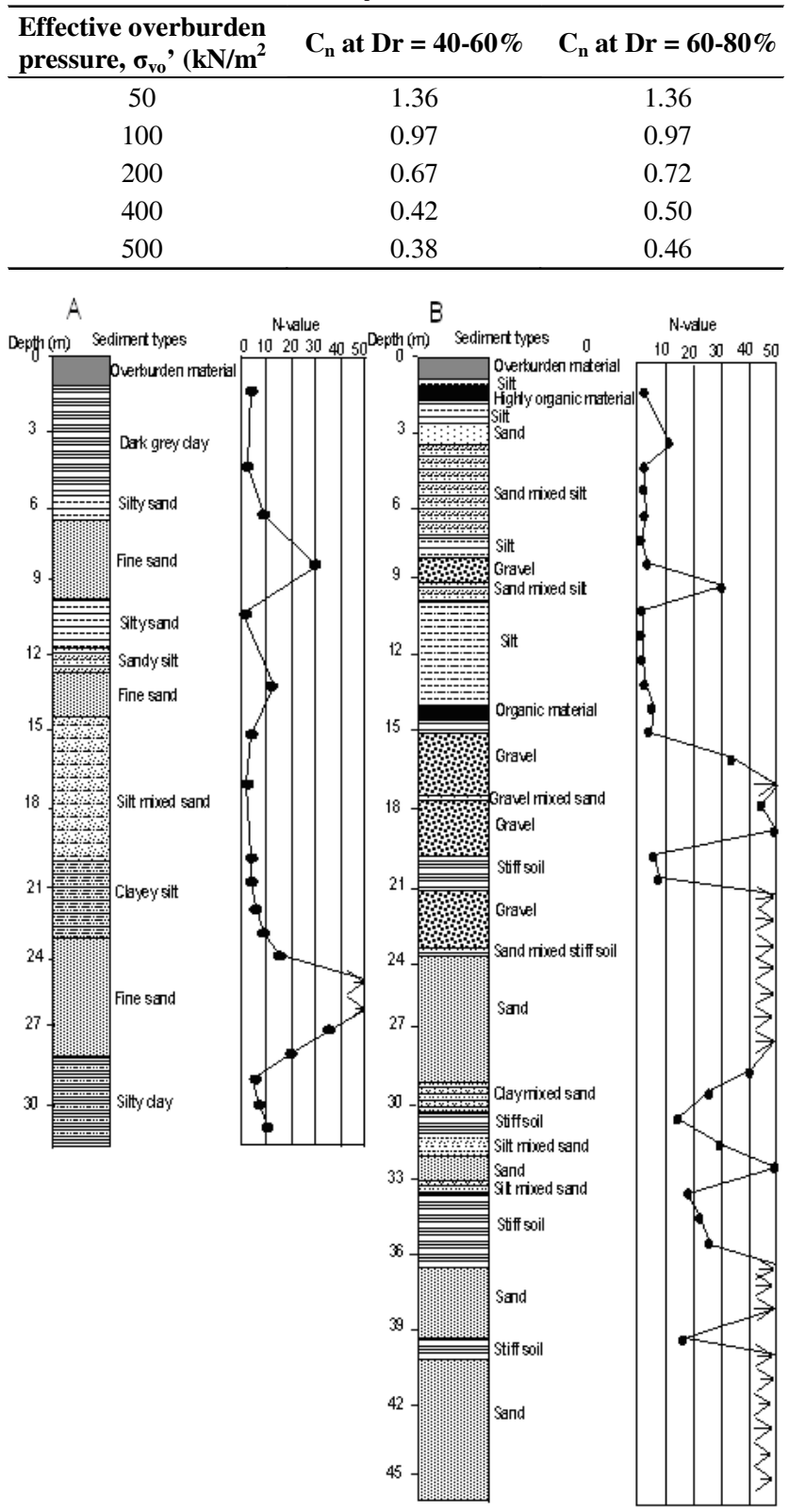

Fig. 3: Typical borehole $\log$ of the Saitama City $(\log$ A from Saitama University and $\log B$ from Urawa from Fig. 1, arrow indicates the $\mathrm{N}$-value greater than $\mathbf{5 0}$ ).

Where, $\mathrm{C}_{\mathrm{n}}$ is correction coefficient for overburden pressure as in Table 2.

$D_{r}=21 \sqrt{N /\left(\sigma_{v}^{\prime}+0.7\right)}$

Where $\mathrm{N}$ is SPT- $\mathrm{N}$ value and $\sigma_{\mathrm{r}}$, is an effective overburden pressure in $\mathrm{kg} / \mathrm{cm}^{2}$, and $\mathrm{ER}_{\mathrm{m}} / 60$ is the correction factor for actual energy efficiency delivered to the drill rod and is considered to be equal to the value 1.2 (Seed et al. 1985; Skempton 1986) and $\mathrm{N}_{\mathrm{m}}$ is measured as $\mathrm{N}$-value in the field. 


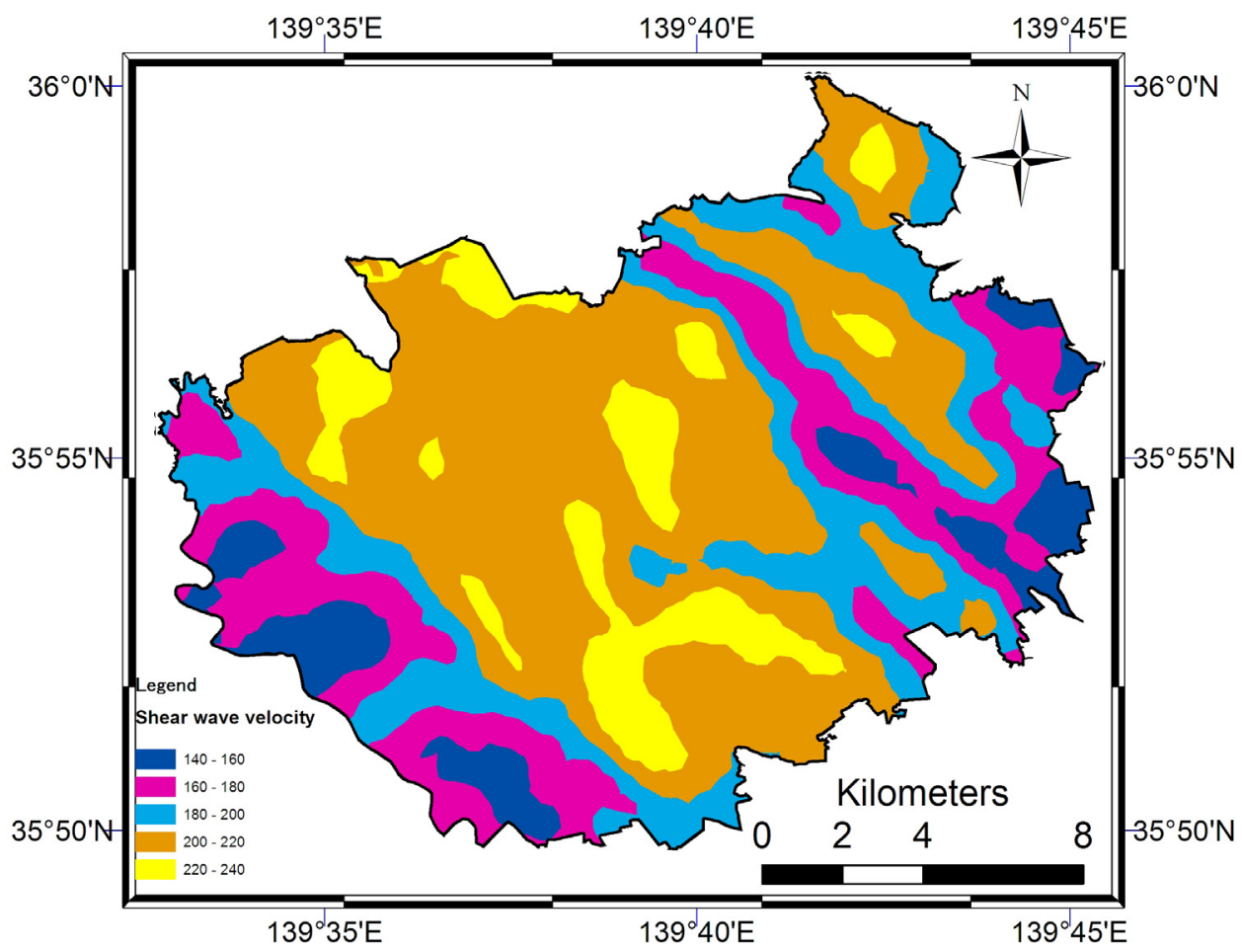

Fig. 4: Average shear wave velocity map

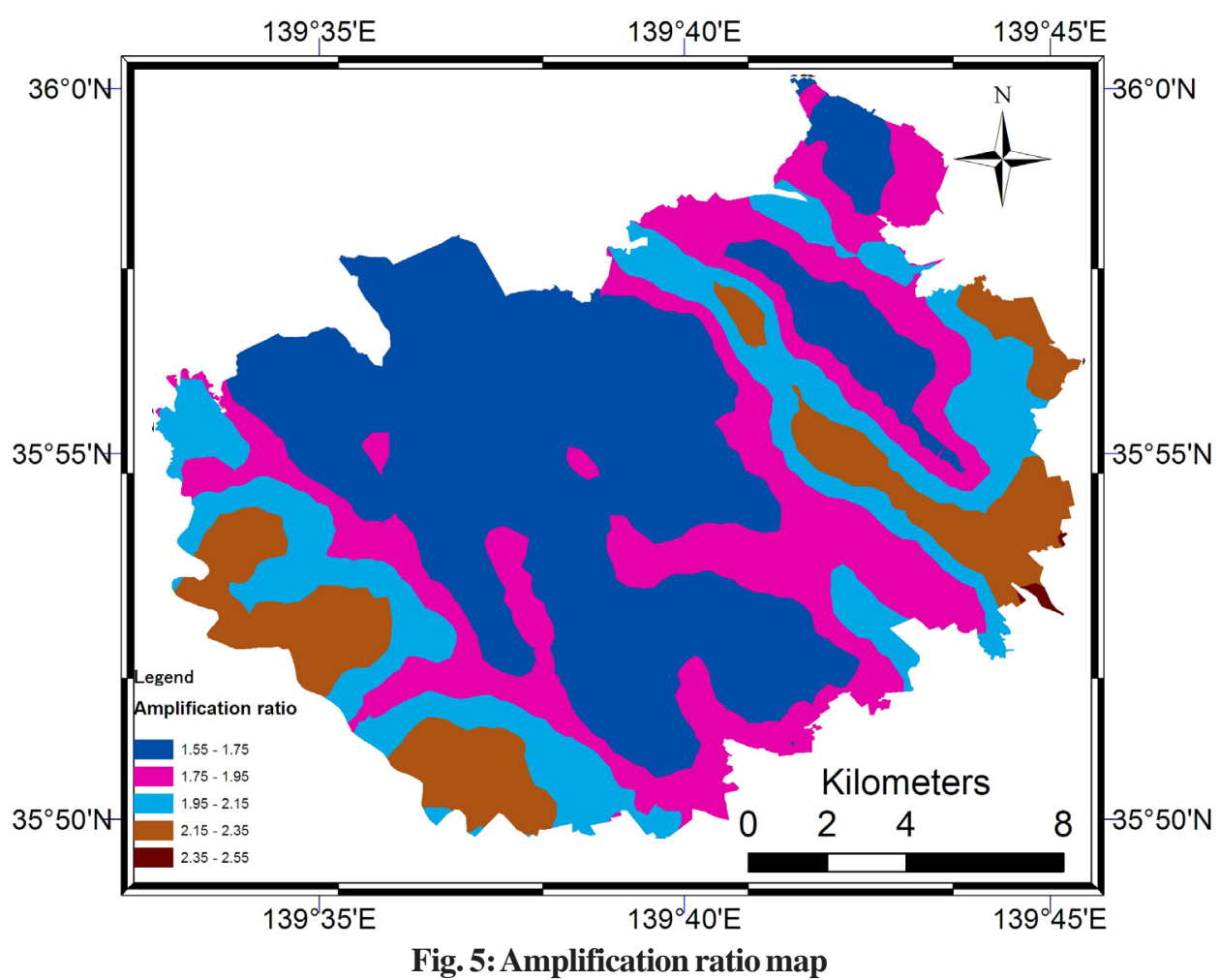




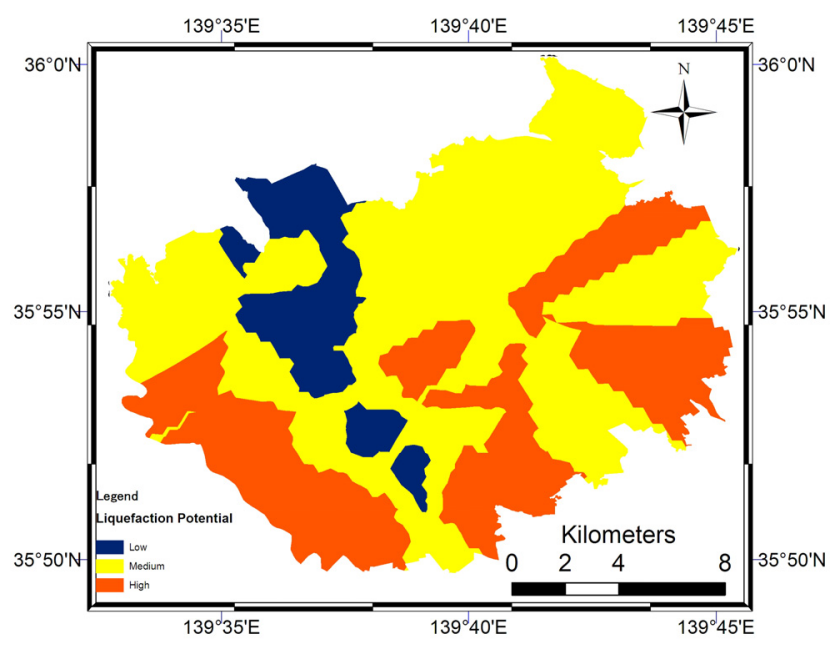

Fig. 6: Liquefaction potential map for $0.15 \mathrm{~g}$ maximum acceleration

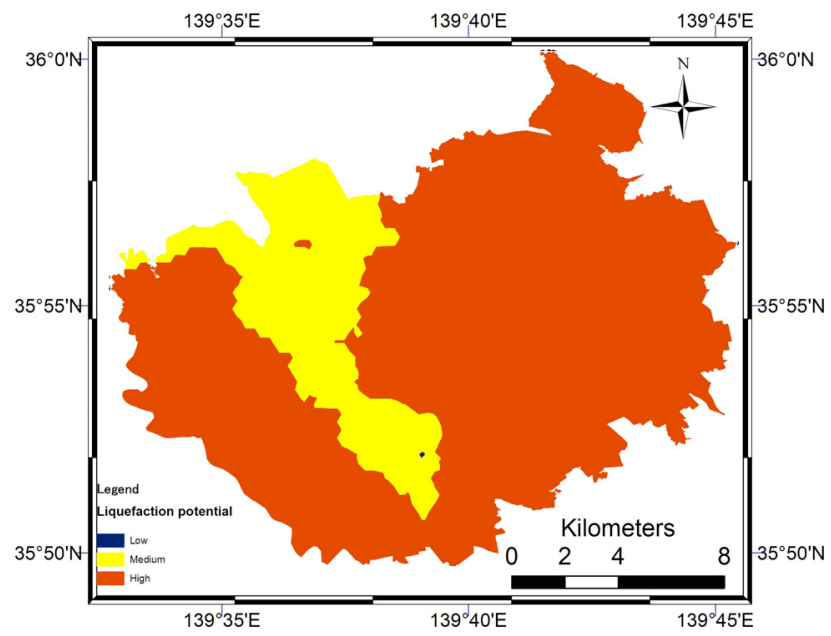

Fig. 8: Liquefaction potential map for $0.25 \mathrm{~g}$ maximum acceleration

The factor of safety for liquefaction for the given earthquake is calculated according to Seed and Idriss (1971),

$F S=\left[\frac{C R R_{7.5}}{C S R}\right] * M S F$

Where, $\mathrm{CRR}_{75}$ is the Cyclic Resistant Ratio value for the earthquake magnitude 7.5, CSR is the Cyclic Stress Ratio for any given earthquake and MSF is Magnitude Scaling Factor. The magnitude of the earthquake for the present study is considered as 7.4 with the epicenter about $50 \mathrm{~km}$ from the Saitama City centre. The maximum acceleration generated by the earthquake in the study area is $0.15 \mathrm{~g}$ to $0.3 \mathrm{~g}$.

\section{Liqufication hazard zonation}

When considering the linear soil behavior, the most important parameter influencing the amplification of ground

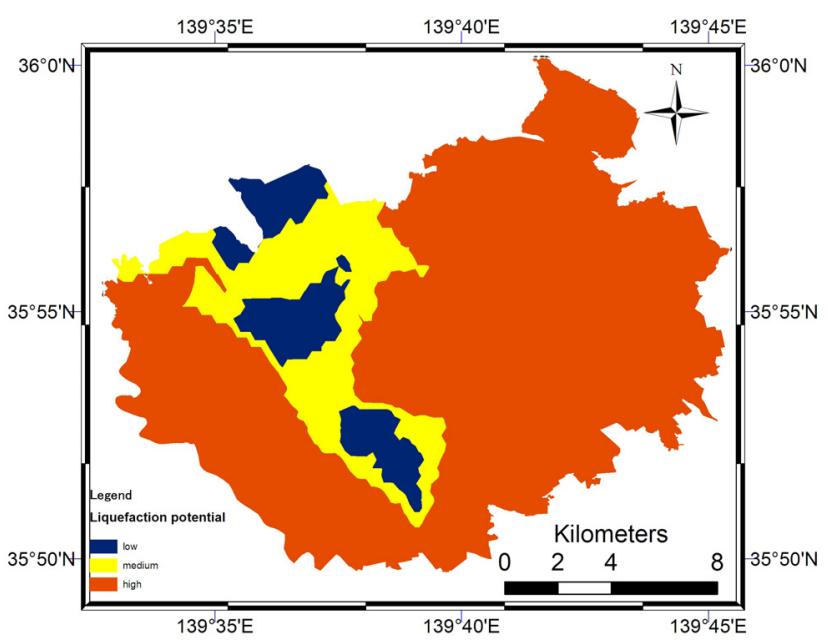

Fig. 7: Liquefaction potential map for $0.2 \mathrm{~g}$ maximum acceleration

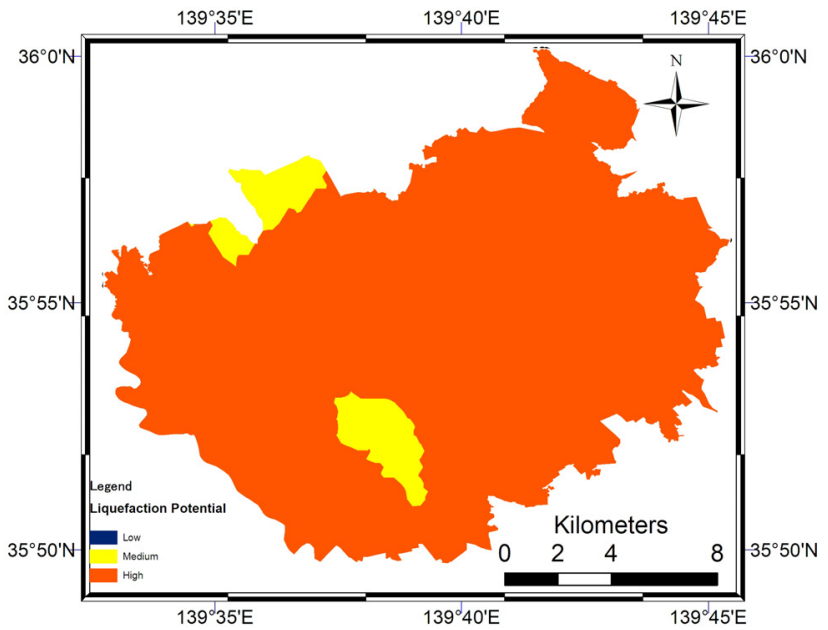

Fig. 9: Liquefaction potential map for $0.3 \mathrm{~g}$ maximum acceleration

motion during earthquakes is the shear wave velocity of the uppermost soil layers (Aki and Richards 1980; Joyner and Fumal 1985; Wills et al. 2000). The depth of bed rock is found below $3500 \mathrm{~m}$ from the ground surface in the study area. The depth upto $3500 \mathrm{~m}$ from the ground surface is considered as a soil layer having shear wave velocity greater than $400 \mathrm{~m} / \mathrm{s}$. The average shear wave velocity for $30 \mathrm{~m}$ depth was provided from Japan Seismic Hazard Information Station (J-SHIS). The average shear wave velocities and amplification ratio for every $250 \mathrm{~m}$ grid cell were also provided (Figs. 4 and 5).

Liquefaction susceptibility of an area is a measure of a soil's inherent resistance to liquefaction, and can range from not susceptible to highly susceptible. The susceptibility has been developed by comparing the properties of the $20 \mathrm{~m}$ surface soil of the study area with other soil deposits where liquefaction had been observed in the past (Seed et al. 1985). 
Table 3: Calculation of liquefaction potential value for one borehole for $0.15 \mathrm{~g}$ (BH no. 3002)

\begin{tabular}{|c|c|c|c|c|c|c|c|c|c|c|c|c|c|c|c|c|c|}
\hline $\begin{array}{c}\text { Depth } \\
\text { (m) }\end{array}$ & $\begin{array}{c}\text { Average } \\
\text { density }\end{array}$ & $\underset{(\mathrm{m} / \mathrm{S} 2)}{\mathrm{g}}$ & $\begin{array}{l}\text { stress } \\
\text { at } 1 \mathrm{~m}\end{array}$ & $\begin{array}{c}\text { overburden } \\
\text { stress }\left(\mathbf{s}_{0}\right)\end{array}$ & $\begin{array}{l}\text { Depth from } \\
\text { water table }\end{array}$ & $\begin{array}{c}\text { Pore } \\
\text { pressure }\end{array}$ & $\begin{array}{c}\text { Effective } \\
\text { stress (s } \\
\left.\text { KN/m2 }{ }^{1}{ }^{\prime}\right)\end{array}$ & $\begin{array}{c}\mathrm{N}- \\
\text { value }\end{array}$ & $\begin{array}{l}\left(\mathrm{N}_{1}\right)_{60} \\
\text { value }\end{array}$ & Dr\% & rd & $\mathrm{CRR}_{7.5}$ & $\begin{array}{l}\text { CSR } \\
0.15 g\end{array}$ & $\begin{array}{c}\text { FS } \\
0.15 g\end{array}$ & Wz & $\begin{array}{c}\text { FZ } \\
0.15 \mathrm{~g}\end{array}$ & $\begin{array}{c}\text { PL } \\
0.15 \mathrm{~g}\end{array}$ \\
\hline 1.3 & 1.6 & 9.8 & 15.68 & 20.384 & 0 & 0 & 20.384 & 2 & 3 & 31 & 0.9805 & 0.04 & 0.097 & 0.410 & 9.35 & 0 & 0 \\
\hline 2.3 & 1.6 & 9.8 & 15.68 & 36.064 & 0.2 & 1.96 & 34.104 & 7 & 11 & 54 & 0.9655 & 0.17 & 0.101 & 1.673 & 8.85 & 0 & 0 \\
\hline 3.3 & 1.6 & 9.8 & 15.68 & 51.744 & 1.2 & 11.76 & 39.984 & 11 & 18 & 66 & 0.9505 & 0.2 & 0.122 & 1.634 & 8.35 & 0 & 0 \\
\hline 4.3 & 1.6 & 9.8 & 15.68 & 67.424 & 2.2 & 21.56 & 45.864 & 2 & 3 & 27 & 0.9355 & 0.07 & 0.136 & 0.511 & 7.85 & 0.488 & 3.833 \\
\hline 5.3 & 1.6 & 9.8 & 15.68 & 83.104 & 3.2 & 31.36 & 51.744 & 2 & 3 & 27 & 0.9205 & 0.07 & 0.147 & 0.475 & 7.35 & 0.524 & 3.851 \\
\hline 7.3 & 1.6 & 9.8 & 15.68 & 114.464 & 5.2 & 50.96 & 63.504 & 1 & 2 & 18 & 0.8905 & 0.06 & 0.159 & 0.375 & 6.35 & 0.624 & 3.964 \\
\hline 8.3 & 1.6 & 9.8 & 15.68 & 130.144 & 6.2 & 60.76 & 69.384 & 3 & 5 & 31 & 0.8755 & 0.1 & 0.163 & 0.612 & 5.85 & 0.387 & 2.269 \\
\hline 9.3 & 1.5 & 9.8 & 14.7 & 136.71 & 7.2 & 70.56 & 66.15 & 30 & 49 & 98 & 0.8605 & 0 & 0.176 & 0 & 5.35 & 0 & 0 \\
\hline 10.3 & 1.5 & 9.8 & 14.7 & 151.41 & 8.2 & 80.36 & 71.05 & 1 & 2 & 18 & 0.8455 & 0.06 & 0.179 & 0.334 & 4.85 & 0.665 & 3.226 \\
\hline 11.3 & 1.6 & 9.8 & 15.68 & 177.184 & 9.2 & 90.16 & 87.024 & 1 & 1 & 17 & 0.8305 & 0.05 & 0.168 & 0.297 & 4.35 & 0.702 & 3.057 \\
\hline 12.3 & 1.6 & 9.8 & 15.68 & 192.864 & 10.2 & 99.96 & 92.904 & 1 & 1 & 16 & 0.8155 & 0.05 & 0.168 & 0.296 & 3.85 & 0.703 & 2.707 \\
\hline 13.3 & 1.6 & 9.8 & 15.68 & 208.544 & 11.2 & 109.76 & 98.784 & 2 & 2 & 23 & 0.8005 & 0.065 & 0.168 & 0.386 & 3.35 & 0.613 & 2.054 \\
\hline 15.3 & 1.6 & 9.8 & 15.68 & 239.904 & 13.2 & 129.36 & 110.544 & 4 & 5 & 31 & 0.7705 & 0.13 & 0.166 & 0.781 & 2.35 & 0.218 & 0.513 \\
\hline 16.3 & 2 & 9.8 & 19.6 & 319.48 & 14.2 & 139.16 & 180.32 & 34 & 27 & 77 & 0.7555 & 0 & 0.133 & 0 & 1.85 & 0 & 0 \\
\hline 17.3 & 2 & 9.8 & 19.6 & 339.08 & 15.2 & 148.96 & 190.12 & 53 & 43 & 94 & 0.7405 & 0 & 0.131 & 0 & 1.35 & 0 & 0 \\
\hline 18.3 & 2 & 9.8 & 19.6 & 358.68 & 16.2 & 158.76 & 199.92 & 44 & 35 & 84 & 0.7255 & 0 & 0.129 & 0 & 0.85 & 0 & 0 \\
\hline 19.3 & 2 & 9.8 & 19.6 & 378.28 & 17.2 & 168.56 & 209.72 & 50 & 40 & 88 & 0.7105 & 0 & 0.127 & 0 & 0.35 & 0 & 0 \\
\hline \multicolumn{17}{|c|}{ Liquefaction potential $\left(\mathrm{P}_{\mathrm{L}}\right)$} & 29.52 \\
\hline
\end{tabular}

Liquefaction hazard zonation mapping has been prepared by many researchers using the N-value (Brankman et al. 2004, Pearce and Baldwin 2005, Yilmaz and Bagei 2006, Sitharam et al. 2007). Similar kind of approach is followed in this paper. The liquefaction hazard maps for different acceleration values were prepared by considering the Kanto Plain NW Edge Fault that cause earthquake of magnitude 7.4. The factor of safety for each layer from each borehole $\log$ has been calculated. The liquefaction potential index $\left(\mathrm{P}_{\mathrm{L}}\right)$ used for quantification of liquefaction potential has been calculated (Iwasaki et al. 1982) according to the equation 5.

$P_{L}=\int_{0}^{20} F(z) W(z) d z$

Where $\mathrm{z}$ is the depth in metre below ground surface, and $W(z)$ is a depth-weighting factor equal to $10-0.5 z$. $F(z)$ is a function of factor of safety against liquefaction. $F_{L}(z)$ is defined as $F(z)=1-F_{L}(z)$ for $F_{L}(z) \leq 1$ and $F(z)=$ 0 for $\quad F_{L}(z)>1$. Equation (5) considers just the profile in the top $20 \mathrm{~m}$, and weighs factor of safety and thickness of potentially liquefiable layers according to the proximity of layers to the ground surface. $\mathrm{P}_{\mathrm{L}}$ values calculated using equation 5 theoretically ranges from 0 to 100 . The minimum value of 0 is obtained where $F_{L}(z)>1$ over the entire $20 \mathrm{~m}$ depth and the maximum value of 100 is obtained where $F_{L}(z)=0$ over the entire $20 \mathrm{~m}$ depth. In this study the soil layer above water table was considered as no liquefiable layer and factor of safety against liquefaction was considered as greater than 1 . The example of the liquefacation potential value calculated for each borehole is shown in Table 3. The $\mathrm{P}_{\mathrm{L}}$ value range from $<15,15-30$ and $>30$ are classified as low, medium, and high liquefaction potentail respectively.

\section{RESULTS AND DISSCUSIONS}

Figs. 6, 7, 8 and 9 show the maps of the liquefaction potential against the maximum ground acceleration of $0.15 \mathrm{~g}, 0.2 \mathrm{~g}, 0.25 \mathrm{~g}$ and $0.3 \mathrm{~g}$, respectively. These predicted liquefaction potential categories in the sediments of the study area is obtaioned by using the Ordinary Kriging method in GIS. The category associated with the liquefaction potential index $\left(\mathrm{P}_{\mathrm{L}}\right)$ value at each boring location was used in the analysis. Liquefaction hazard potential in the study area is classified into low, medium and high. Low liquefaction hazard potential exists in the middle part of the study area lying in the Omoya Plateau whereas zones of high liquefaction potential exist in the western and eastern part of the region. In the lower liquefaction potential area, the sediments of marine loams are deposited at the surface, while sand and gravel are accumulated at the depth in the Omaya Plateau. The high liquefaction potetial at the western portion is due to the presence of very loos clayey silt layer through out its 15 depth upto $20 \mathrm{~m}$ and shallow groundwater table. The area is comprised by marsh envieronment of the Arakawa River. Fig. 9 indicates that most of the area of the Saitama City falls under the high liquefaction potential zoning at the acceleration value of $0.3 \mathrm{~g}$ related to the earthquake of magnitude $>8$. Minuma and Shiva river valleys, eastern portions of the study area have high liquefaction potential.

Fig. 6 shows that the area in the south western part which is a former flood plain of the Arakawa River, has very high liquefaction potential even for $0.15 \mathrm{~g}$. In fact, here is the presence of liquefiable strata (very loose clayey silt layer) up to $30 \mathrm{~m}$ depth water table is lying at shallow depth. The terrace deposit and middle part of the study area have low liquefaction potential for $0.15 \mathrm{~g}$ acceleration, moderate for $0.2 \mathrm{~g}$ and $0.25 \mathrm{~g}$, and high for $0.3 \mathrm{~g}$ acceleration values. 


\section{CONCLUSIONS}

Soil liquefaction is one of the most devastating effects of earthquake which causes enormous loss of life and property especially in the city built on the alluvial deposits. Liquefaction potential of alluvial soil deposit at Saitama City is characterized by the study using geotechnical data including analysis of the SPT N-value and shear wave velocity. The liquefaction potential assessment has been carried out by considering the Kanto Plain NW Edge Fault Earthquake of magnitude $(M w)$ 7.4. The considered fault is situated at a distance of $50 \mathrm{~km}$ from the city centre. Liquefaction potential hazard map has been prepared based on the soil types, depth, layer properties, N-values, depth of water table, and maximum ground acceleration. The possible ground accelerations considered for the assumed earthquake are $0.15 \mathrm{~g}, 0.2 \mathrm{~g}, 0.25 \mathrm{~g}$ and $0.3 \mathrm{~g}$. The western portion of the site with ancient flood plain deposits and marshy land of the Arakawa River with clayey silt deposits are mapped in the high hazard zone for all considered acceleration values. The Omiya Plateau consisting loam, fine sand and gravel layer on the shallow depth lies in medium liquefaction hazard potential zone for $0.15 \mathrm{~g}$, and $0.2 \mathrm{~g}$ while it lies in high liquefaction potential hazard zone in case of acceleration of $0.25 \mathrm{~g}$, and $0.3 \mathrm{~g}$.

\section{ACKNOWLEDGEMENTS}

The first author acknowledges to the Ministry of Education, Culture, Sports, Science and Technology (Monbukagakusho) of Japan for its support by providing scholarship for this research work. The authors are also thankful to Mr. Maijima for his help during the time of data collection. The authors are thankful to the one anonymous reviewer and Mr. Birendra Piya from Department of Mines and Geology, Government of Nepal for their valuable comments to improve the maninscript.

\section{REFERENCES}

Aki, K. and Richards, P. G., 1980, Quantitative Seismology: Theory and Methods. v. 1, W.H. Freeman, New York, 557 p.

Boore, D. M., Joyner, W. B., and Fumal, T. E., 1997, Equations for Estimating Horizontal Response Spectra and Peak Acceleration from Western North American Earethquakes: A Summary of recent Work. Seismological Research Letters, v. 68 (1), pp. 28-153.

Brankman, C. M., Baise, L. G., Higgins, R. B., and Dawson, K. M., 2004, Liquefaction Hazard Mapping in Boston, Massachusetts: Collaborative Research with William Lettis Associates and Tufts University. Published in web page (http:/ /earthquake.usgs.gov/research/external/reports/ 02HQGR0040.pdf).

Hammer, J., 2006, Yokohama Burning: The Deadly 1923 Earthquake and Fire that Helped Forge the Path to World War II. Simon and Schuster, New York. pp. 336.

Iwasaki, T., Tokida, K., Tatsuoka, F., Watanabe, S., Yasuda, S., and Sato, H., 1982, Microzonation for soil liquefaction potential using simplified methods. Proceedings of $3 \mathrm{rd}$
International Earthquake Microzonation Conference, Seattle, pp. 1319-1330.

Japan Seismic Hazard Information Station (J-SHIS ), 2009, (http:/ /www.j-shis.bosai.go.jp/

Joyner, W. B. and Fumal, T. E., 1985, Predictive mapping of earthquake ground motion. U. S. Geol. Surv. Prof. Paper 1360, pp. 203-220.

Kienzle, A., Hannich, D., Wirth, W., Ehret, D., Joachim Rohn, Ciugudean, V., and Czurda, K., 2006, A GIS-based study of earthquake hazard as a tool for the microzonation of Bucharest. Engineering Geology, v. 87, pp. 13-32.

Kramer, S. L., 1996, Geotechnical Earthquake Engineering. Prentice Hall, Upper Saddle River, 652 p.

Machida, M., 1999, Quaternary Geology in the central to western parts of the Kanto Tectonic Basin. A dissertation submitted to the Doctoral Program in Geoscience, the University of Tsukuba, $113 \mathrm{p}$

Pearce, J. T. and Baldwin, J. N., 2005, Liquefaction Susceptibility Mapping ST. Louis, Missouri and Illinois. Final Technical Report, published in web.er.usgs.gov/reports/ abstract/2003/ cu/03HQGR0029.pdf.

Power, M. S. and Holzer, T. L., 1996, "Liquefaction maps". ATC Tech-Brief 1, Applied Technology Council, Redwood City, CA., 12 p.

Seed, H. B. and Idriss, I. M., 1971, Simplified Procedure for Evaluating soil liquefaction potential. Jour. SMFD, ASCE, v. 97(9), pp. 1249-1273.

Seed, H. B., Tokimatsu, K., Harder, L. F., and Chung, R. M., 1984, The Influence of SPT Procedures in Soil Liquefaction Resistance Evaluations. Report no. UCB/EERC-84/15. Earthquake Engineering Research Center, Berkeley, California. $50 \mathrm{p}$.

Seed, H. B., Tokimatsu, K., Harder, L. F., and Chung, R. M., 1985, Influence of SPT procedures in soil liquefaction resistance evaluations. J. Geotechnical Engineering, ASCE, 111(12), pp. $1425-1445$.

Sitharam, T. G., Anbazhagan. P., and Mahesh. G. U., 2007, 3-D Subsurface Modelling and Preliminary Liquefaction Hazard Mapping of Bangalore City Using SPT Data and GIS, Indian Geotechnical Journal, v. 37(3), pp. 210-226.

Skempton, A. W., 1986, Standard Penetration Test Procedures, Geotechnique, v. 36, pp. 425-447.

Wills, C. J., Petersen, M., Bryant,W. A., Reichle, M., Saucedo, G. J., Tan, S., Taylor, G., Treiman, J., 2000, Asite-conditionsmap for California based on Geology and shear-wave velocity. Bull. Seismol. Soc. Am. v. 90(6), pp. 187-208.

Yilmaz, I. and Bagei, A., 2006, Soil Liquefaction Susceptibility and Hazard Mapping in the Residential Area of Kiitahiya (Turkey), Environmental Geology, v. 49, pp. 708-719.

Youd, T. L. and Hoose, S. N., 1977, Liquefaction susceptibility and geologic setting. Proceeding $6^{\text {th }}$ World Conference on Earthquake Engineering, pp. 2189-2194.

Youd, T. L. and Perkins, D. M., 1978. Mapping liquefactioninduced ground failure potential. Jour. Geotechnical Engineering, ASCE, vol. 104 (4), pp 433-446.

Youd, T. L., Idriss, I. M. Andrus, R. D. Arango, I., Castro, G., Christian, J. T., Dobry, R., Liam Finn, W. D. L., Harder, L. F., Jr., Hynes, M. E., Ishihara, K., Koester, J. P., Liao, S. S. C., Marcuson, W. F., III, Martin, G. R., Mitchell, J. K., Moriwaki, Y., Power, M. S., Robertson, P. K., Seed, R. B., Stokoe, K. H., II, 2001, "Liquefaction resistance of soils: summary report from the 1996 NCEER and 1998 NCEER/NSF workshops on evaluation of liquefaction resistance of soils," ASCE, Journal of Geotechnical and Geoenvironmental Engineering, v. 127(10), pp. 817- 833 . 